\title{
Análise do sistema de validação e refinamento de alertas do Mapbiomas e do laudo de área desmatada em Altamira - PA, Brasil (2018 - 2021)
}

Analysis of the validation and refinement system of Mapbiomas alerts and the deforested area report in Altamira - PA, Brazil (2018 - 2021)

Análisis del sistema de validación y refinamiento de alertas de Mapbiomas y el informe de área deforestada en Altamira - PA, Brasil (2018 - 2021)

\section{Resumo}

A exploração dos recursos naturais reflete diretamente em alterações nos usos e ocupações do solo no Brasil. O desmatamento é uma das consequências dessa exploração, que tem impactado negativamente os Biomas, a biodiversidade, o clima local e global. $\mathrm{O}$ avanço das geotecnologias tem possibilitado o surgimento de grandes aliados para o monitoramento de áreas degradadas no Brasil e no mundo. Foi nesse contexto que surgiu o MapBiomas Alerta, um sistema de validação e refinamento de alertas de desmatamento, degradação e regeneração de vegetação nativa com imagens de alta resolução. Esse artigo tem como objetivo geral analisar essa ferramenta de alertas de desmatamento: descrever como funciona o MapBiomas Alerta; estudo de caso do município que apresentou a maior área desmatada no Brasil (2018 - 2021); e abordar as principais contribuições do MapBiomas Alerta. A metodologia proposta tem uma abordagem qualitativa da ferramenta em estudo, visa analisar, descrever, explicar e demonstrar como ela funciona e suas potencialidades de uso para a gestão ambiental. Os resultados demonstram a gravidade da situação do desmatamento no Brasil, com um total de área degradada nos últimos anos, que corresponde aproximadamente ao tamanho do estado de Alagoas. Sendo o Bioma da Amazônia o mais afetado, com o estado do Pará e o município de Altamira-PA com a maior concentração de alertas e de áreas desmatadas. As contribuições do MapBiomas Alerta são de grande relevância para o monitoramento do desmatamento no território brasileiro e para a acessibilidade desses dados.

Palavras-chave: Sensoriamento remoto; Áreas degradadas; Gestão ambiental; Recursos naturais.

\begin{abstract}
The exploitation of natural resources reflects directly on changes in land use and occupation in Brazil. Deforestation is one of the consequences of this exploitation, which has negatively impacted the Biomes, biodiversity, the local and global climate. The advance of geotechnologies has enabled the emergence of great allies for the monitoring of degraded areas in Brazil and worldwide. It was in this context that the MapBiomas Alert appeared, a system for validating and refining alerts for deforestation, degradation and regeneration of native vegetation with high resolution images. The general objective of this article is to analyze this tool for deforestation alerts: to describe how MapBiomas Alerta works; estudio de caso del municipio que presentó mayor área deforestada en Brasil (2018 - 2021); and address the main contributions of MapBiomas Alerta. The proposed methodology has a qualitative approach to the tool under study, aims to analyze, describe, explain and demonstrate how it works and its potential uses for environmental management. The results demonstrate the gravity of the deforestation situation in Brazil, with a total area degraded in recent years that corresponds approximately to the size of the state of Alagoas. The Amazon Biome is the most affected, with the state of Pará and the municipality of Altamira-PA having the highest concentration of alerts and deforested areas. The
\end{abstract}


contributions of MapBiomas Alerta are of great relevance for monitoring deforestation in Brazilian territory and for the accessibility of this data.

Keywords: Remote sensing; Degraded areas; Environmental management; Natural resources.

\section{Resumen}

La explotación de los recursos naturales refleja directamente en los cambios en los usos y ocupaciones de la tierra en Brasil. La deforestación es una de las consecuencias de esta explotación, que ha tenido un impacto negativo en los biomas, la biodiversidad, el clima local y global. El avance de las geotecnologías ha permitido el surgimiento de grandes aliados para el monitoreo de áreas degradadas en Brasil y en el mundo. Fue en este contexto que surgió MapBiomas Alerta, un sistema para validar y refinar alertas sobre deforestación, degradación y regeneración de vegetación nativa con imágenes de alta resolución. Este artículo tiene el objetivo general de analizar esta herramienta para alertas de deforestación: describir cómo funciona MapBiomas Alerta; case study of the municipality with the largest deforested area in Brazil (2018 - 2021); y abordar las principales aportaciones de MapBiomas Alerta. La metodología propuesta tiene un enfoque cualitativo de la herramienta en estudio, tiene como objetivo analizar, describir, explicar y demostrar cómo funciona y su potencial de uso en la gestión ambiental. Los resultados demuestran la gravedad de la situación de deforestación en Brasil, con un área total de área degradada en los últimos años, que corresponde aproximadamente al tamaño del estado de Alagoas. El Bioma Amazónico es el más afectado, con el estado de Pará y el municipio de Altamira-PA con la mayor concentración de alertas y áreas deforestadas. Los aportes de MapBiomas Alerta son de gran relevancia para el seguimiento de la deforestación en el territorio brasileño y para la accesibilidad de estos datos.

Palabras clave: Teledetección; Zonas degradadas; Gestión ambiental; Recursos naturales.

\section{Introdução}

A intensificação das mudanças de uso e ocupação do solo, no Brasil, ocorreu desde a chegada dos portugueses, em 1500. As alterações das paisagens são marcadas pela apropriação dos territórios e exploração dos recursos naturais. Estas seguem ocorrendo e, atualmente, afetam todos os seis biomas brasileiros: Amazônia, Caatinga, Cerrado, Mata Atlântica, Pampa e Pantanal. As transformações foram mais intensas após três décadas de invasão, quando as Capitanias Hereditárias foram instauradas, com a cultura da cana-de-açúcar e da produção do gado no território brasileiro. Após o ciclo da cana-de-açúcar, ocorreu o do ouro, do algodão e o ciclo do café. Todos esses foram responsáveis pela intensificação das desigualdades pautadas por um sistema escravocrata, de espoliação das riquezas brasileiras por Portugal e pelos portugueses, que se apropriaram das terras e massacraram os povos indígenas (Resende, 2002).

Após mais de 500 anos de exploração, o Brasil permanece um país rico em biodiversidade e recursos naturais. Segundo Souza et al., (2020), os biomas brasileiros concentram as maiores reservas de água doce do mundo e um grande estoque de carbono em suas florestas e solos, além da diversidade de espécies presentes na fauna e na flora. O Brasil também se destaca como um grande produtor agropecuário, no entanto, o desmatamento para a expansão de pastagens e cultivos agrícolas tem gerado impactos negativos para os biomas e ecossistemas existentes (Souza et al., 2020).

Segundo Redding, Atkinson e Cunningham et al., (2019), dois terços das doenças infecciosas humanas têm origem zoonóticas e constituem um grande problema para a saúde e a economia em escala global, afetando de forma desproporcional os países mais pobres e comunidades mais vulneráveis. O surgimento de novas doenças e surtos de doenças já conhecidas intensificam-se com o processo de desmatamento, devido ao desequilíbrio de ecossistemas, com a redução dos predadores de animais hospedeiros de vírus e o maior contato dos seres humanos com esses animais. Essa quebra de barreira pode ocorrer, também, através de vetores artrópodes, que transmitam determinados vírus para o ser humano, como é o caso da Dengue, Zika e Chikungunya, doenças transmitidas pelo mosquito Aedes Aegypti.

A relação do desmatamento com os desequilíbrios ambientais tem sido tema de inúmeras pesquisas científicas, que atribuem ao desmatamento o surgimento de novas epidemias. Com a possibilidade de gerar pandemias, como a do Coronavírus, que o mundo está atravessando desde 2019, com mais de 400 mil óbitos no Brasil e quase 3 milhões de óbitos globalmente. Essa relação do desmatamento com surgimento de novas pandemias é um motivo plausível para que todos os países unam esforços para combater o desmatamento e preservar o equilíbrio dos ecossistemas. Outra prática que deve ser combatida é a caça, a criação 
e o consumo de animais silvestres, pois, o contato com esses animais e a falta de salubridade de mercados, onde eles são comercializados, podem contribuir para a disseminação de doenças infecciosas (Layrargues, 2020). Já que a ocupação de habitats de animais silvestres e o consumo desses animais pelos seres humanos foram correlacionados com a incidência de endemias e epidemias (Bloomfield, McIntosh \& Lambin, 2020).

O Brasil segue na contramão do mundo, no que diz respeito as medidas de combate à pandemia do Coronavírus e ao desmatamento. O governo brasileiro escolheu seguir o caminho do negacionismo e aproveitar que só se falava em pandemia para "passar a boiada" nas legislações ambientais, favorecendo a devastação ambiental e desmonte institucional dos órgãos ambientais. O aumento crescente das taxas de desmatamento, desde 2019, são reflexos desse governo que incentiva práticas antiecológicas e tem contribuído para promover um verdadeiro ecocídio (Layrargues, 2020).

As extensas áreas degradadas, no Brasil, podem ser observadas por meio de imagens de satélites, que permitem acompanhar o ambiente e suas transformações ao longo do tempo. Essas transformações podem ser causadas por eventos naturais, como inundações e erosões do solo, ou por interferências antrópicas, como: desmatamento, queimadas, expansão agropecuária e urbana, além de outras mudanças no uso e ocupação do solo. Com os avanços das geotecnologias, os sensores remotos tornaram-se capazes de produzir dados com melhores resoluções e maior precisão, o que permite o desenvolvimento de mapas e estudos em diversas áreas do conhecimento de forma mais rápida e cada vez mais acessíveis (Florenzano, 2005).

Atualmente, algumas ferramentas de geotecnologias podem ser acessadas por meio de softwares livres ou plataformas onlines, em sites e/ou aplicativos. Foi nesse contexto que uma iniciativa multi-institucional, envolvendo universidades, ONGs e empresas de tecnologia, criou o projeto MapBiomas Alerta, com lançamento em 07 de junho de 2019. Esse projeto desenvolveu um sistema de validação e refinamento de alertas de desmatamento, degradação e regeneração de vegetação nativa com imagens de alta resolução (MAPBIOMAS, 2019). Tal sistema pode ser consultado no site do MapBiomas Alerta de forma livre e gratuita (MAPBIOMAS, 2021a). Além de permitir que o usuário interaja com a ferramenta, apresenta dados e laudos relevantes para estudos ambientais, que podem ser utilizados para o monitoramento e a fiscalização de áreas degradadas.

Devido a significativa importância desta plataforma online para a comunidade acadêmica, científica e a população civil em geral, esse artigo objetivou analisar a ferramenta de alertas de desmatamento do Projeto MapBiomas Alerta. Mais especificamente, visa: descrever como funciona essa ferramenta; discutir os dados do laudo de uma das maiores áreas desmatadas no Brasil entre novembro de 2018 e janeiro de 2021; e abordar as principais contribuições do MapBiomas Alerta.

\section{Metodologia}

A metodologia proposta tem uma abordagem qualitativa, aplicada ao MapBiomas Alerta, com o objetivo de analisar, descrever, explicar e explorar essa ferramenta, que gera alertas e laudos de desmatamento, para demonstrar como ela funciona e suas potencialidades de uso para a gestão ambiental nos biomas brasileiros. Os procedimentos metodológicos adotados referemse ao acesso a Plataforma de forma online, onde foram selecionados os filtros para identificar os alertas de desmatamento em todo o território brasileiro e de forma individual por bioma, no período de dezembro de 2018 a janeiro de 2021 (MAPBIOMAS, 2021a). Os filtros possíveis de serem aplicados são: data de detecção ou data de publicação; período; tipo de território; território; cruzamentos; tamanho do alerta; autorização; e área embargada (Figura 1). 
Figura 1: Plataforma MapBiomas Alerta.

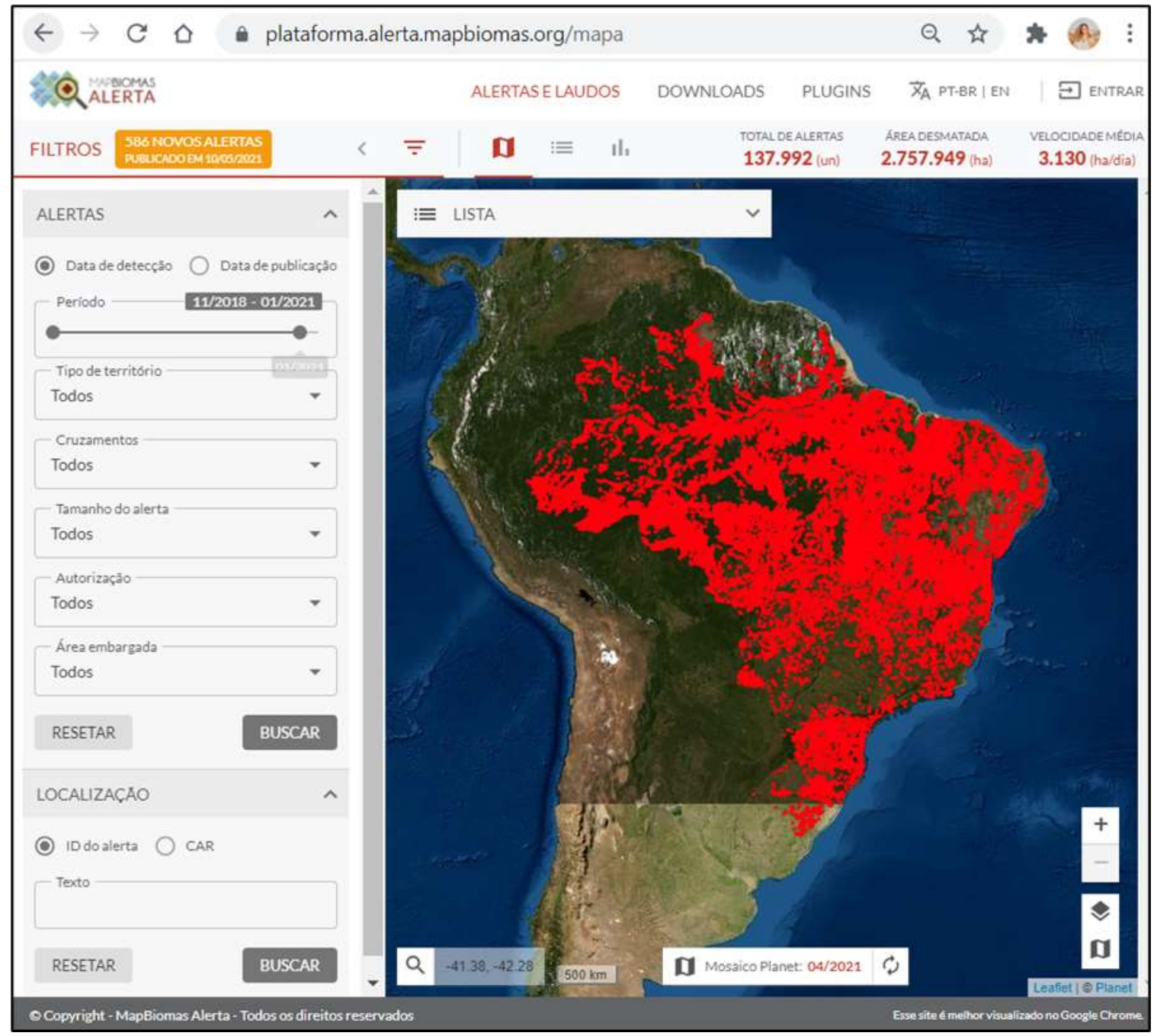

Fonte: MAPBIOMAS (2021a).

Após selecionar todos em tipo de território, foi possível acessar os alertas de desmatamentos de todos os biomas brasileiros, emitidos no período em estudo, o que permitiu identificar onde ficam os alertas das cinco maiores áreas desmatadas no Brasil (Quadro 1). Dentre as cinco áreas, foram pontuados os critérios de maior concentração de áreas desmatadas por município e a qualidade dos laudos gerados automaticamente pela Plataforma MapBiomas Alerta para definir qual seria o município a ser analisado como estudo de caso.

No bioma da Amazônia, estado do Pará, o município de Altamira concentra duas grandes áreas desmatadas; e no bioma do Cerrado, o Maranhão possui duas áreas distribuídas em quatro municípios (Alto Parnaíba, Balsa, Benedito Leite e São Félix de Balsas), e a Bahia apresenta uma área com alerta de desmatamento, no município Formosa do Rio Preto (Quadro 1). Os dois alertas referentes ao município de Altamira somam 10919,88 hectares, que corresponde a uma área aproximadamente de 109,2 $\mathrm{Km}^{2}$, o mesmo que 15.293 campos de futebol (com área de $7.140 \mathrm{~m}^{2}$ ou $0,00714 \mathrm{Km}^{2}$ ). Por essa razão, Altamira foi o município selecionado para o estudo de caso. O primeiro alerta do município (ID 120740) possui uma área aproximada de 64,7 $\mathrm{Km}^{2}$, mas apresentou laudo incompleto, com poucos dados e imagens georreferenciadas da área, enquanto o segundo alerta (ID 27847), possui uma área de $44,5 \mathrm{Km}^{2}$ e apresentou um laudo mais completo. 
Quadro 1: Cinco maiores áreas desmatadas de acordo com alertas do MapBiomas.

\begin{tabular}{|c|c|c|c|c|c|}
\hline ID do Alerta & $\begin{array}{c}\text { Área } \\
\text { (ha) }\end{array}$ & $\begin{array}{c}\text { Data de } \\
\text { deteç̧ão }\end{array}$ & Estados & Cidades & Bioma \\
\hline 120740 & 6468,61 & $01 / 01 / 2020$ & PA & Altamira & Amazônia \\
\hline 118502 & 5987,13 & $26 / 04 / 2020$ & MA & Alto Parnaíba e Balsas & Cerrado \\
\hline 117978 & 5083,54 & $11 / 02 / 2020$ & BA & Formosa do Rio Preto & Cerrado \\
\hline 116961 & 4466,90 & $08 / 03 / 2020$ & MA & $\begin{array}{c}\text { Benedito Leite e São } \\
\text { Félix de Balsas }\end{array}$ & Cerrado \\
\hline 27847 & 4451,27 & $01 / 06 / 2019$ & PA & Altamira & Amazônia \\
\hline
\end{tabular}

Fonte: MAPBIOMAS (2021a).

Os laudos gerados automaticamente pela Plataforma do MapBiomas Alerta apresentam apenas informações georreferenciadas sobre a área, a interpretação dos dados e o desenvolvimento de estudos ficam a critério dos usuários (MAPBIOMAS, 2021b).

A definição da área de estudo baseou-se na necessidade de uma abordagem inicial do panorama geral do desmatamento, a partir dos dados de alerta dos seis biomas brasileiros: Amazônia, Cerrado, Caatinga, Mata Atlântica, Pampa e Pantanal (Figura 2), no período entre novembro de 2018 e janeiro de 2021. Após essa abordagem geral, foi realizado o estudo de caso do município de Altamira - PA, em relação a situação dos alertas de desmatamento no município, no estado e no bioma onde está localizado. Esse estudo de caso foi finalizado com a análise do laudo (gerado pelo MapBiomas Alerta) de uma das maiores áreas desmatadas no município.

\section{1 Área de Estudo}

A Amazônia, (Figura 2), corresponde a 49\% do território brasileiro, é a maior floresta tropical do mundo e equivale a 1/3 (um terço) de todas as florestas tropicais úmidas que existem. Além disso, esse Bioma possui uma biodiversidade rica, com mais de 13 mil espécies de flora e quase 3 mil espécies endêmicas, e sua fauna soma milhares de espécies de peixes, aves, répteis, mamíferos e anfíbios (IBGE, 2021). O Cerrado, (Figura 2), corresponde a 24\% do território brasileiro, é considerado, segundo o IBGE (2021), a savana mais rica do mundo em biodiversidade, com uma flora com mais de 12 mil espécies, sendo mais de 7 mil endêmicas. Até a década de 1950, esse Bioma permaneceu quase inalterado, após a construção de Brasília e abertura de novas rodovias, houve a intensificação da sua ocupação e o avanço das fronteiras da agropecuária intensiva.

A Caatinga, (Figura 2), ocupa 10\% do território brasileiro e possui uma flora com mais de 5 mil espécies, sendo mais de 1,5 mil espécies endêmicas, embora esteja em uma região semiárida, este bioma também é afetado pela supressão de vegetação nativa para o uso e ocupação de áreas com atividades da agropecuária intensiva (IBGE, 2021). A Mata Atlântica, (Figura 2), corresponde a cerca de 13\% do território e concentra mais de 50\% da população nacional, segundo dados do IBGE (2021), além disso, possui uma rica biodiversidade, sua flora tem quase 19 mil espécies, sendo mais de 10 mil espécies endêmicas. Porém menos de $30 \%$ da sua cobertura vegetal nativa encontra-se preservada, já que esse Bioma sofre com os impactos das mudanças intensivas de uso e ocupação do solo desde o período colonial. 
Figura 2: Biomas Brasileiros.

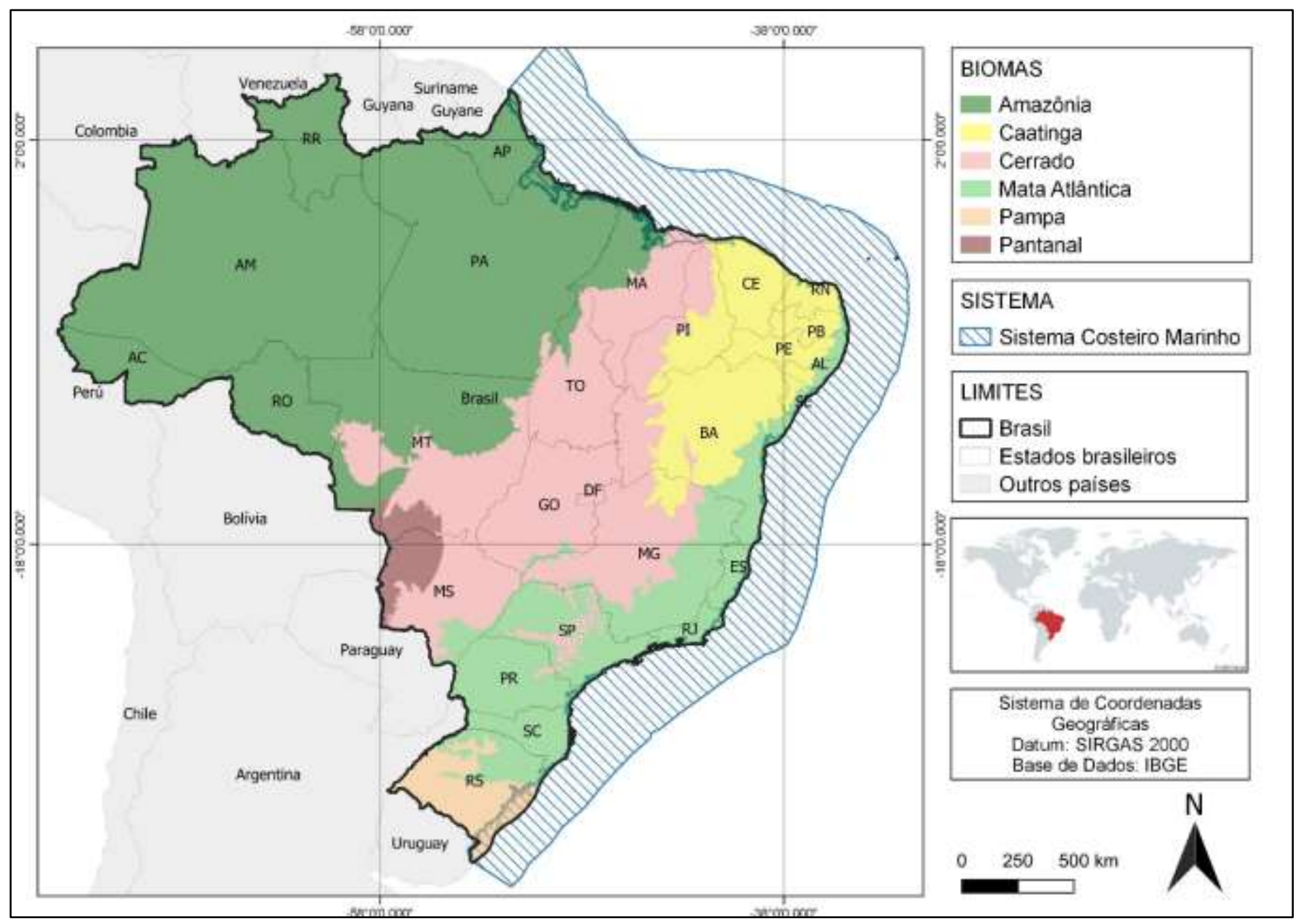

Fonte: Base de dados do IBGE, versão editada pelos autores com o uso do Quantum Gis (QGis) (2021).

O Pampa, assim como o Pantanal, ocupa cerca de $2 \%$ do território brasileiro, sendo que o Pampa possui uma uniformização da paisagem provocada pelas atividades antrópicas de agricultura e pecuária, embora possua mais de 1,6 mil espécies de flora. O Pantanal é a maior planície de inundação, de acordo com o IBGE (2021), possui mais de 1,1 mil espécies de flora, sendo 146 endêmicas, era um dos Biomas mais preservados do país, mas nos últimos anos tem sido afetado por queimadas criminosas e ocupações com a expansão das fronteiras agrícolas, que já atingiam o Cerrado, e, atualmente, tem atingido também o Pantanal e a Amazônia, (Figura 2).

A área de estudo para a abordagem do desmatamento no panorama do Bioma, estado e município que apresenta as maiores áreas desmatadas é respectivamente: a Amazônia, o Pará e o município de Altamira, situado nesse mesmo Estado. Segundo Romão, Pontes, Gutjahr e Torres (2017), o processo de ocupação da Amazônia foi através de incentivos fiscais e políticas de colonização, desencadeando o estímulo ao desmatamento e a alteração da paisagem com as mudanças de uso e ocupação do solo provocadas pela expansão agropecuária, abertura e pavimentação de estradas, projetos hidroelétricos e extração mineral.

Altamira localiza-se na mesorregião do sudoeste do Pará, às margens do Rio Xingu, há cerca de 512 km de distância de Belém, capital do Estado. O município é fruto do processo de colonização da Amazônia, no final do século XVII, segundo Miranda Neto e Herrera, (2017), e, recentemente, foi marcado pelo forte processo migratório (Figura 3). 
Figura 3: Localização de Altamira - PA.

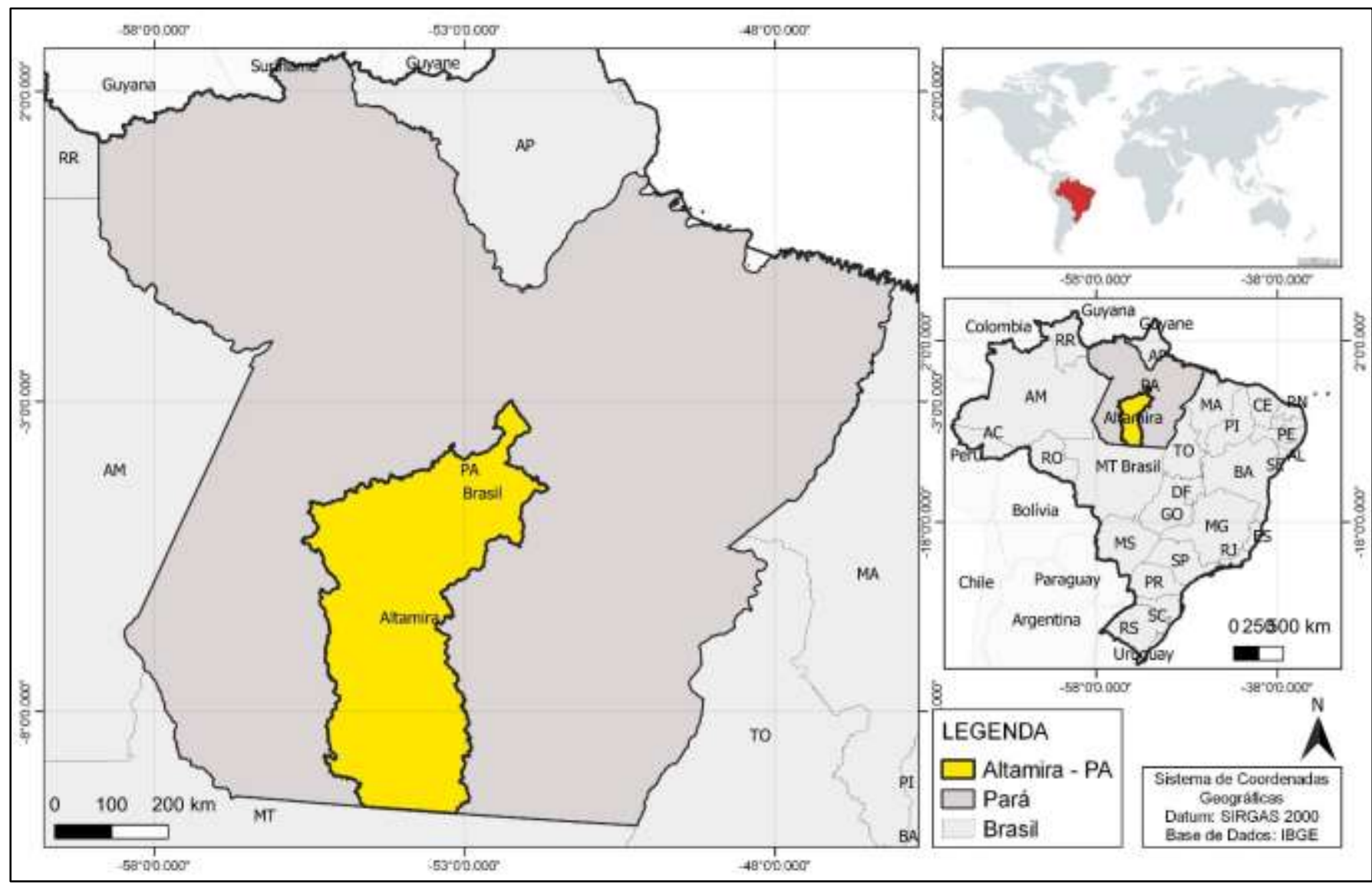

Fonte: Base cartográfica do IBGE, elaborado pelos autores (2021).

Altamira possuía cerca de 7.539 habitantes, em 1950, essa população passou a ser, aproximadamente, treze vezes maior em 2010, quando o censo registrou 99.075 habitantes. Nesse mesmo ano foi liberada a licença de instalação da Usina Hidrelétrica de Belo Monte e, em 2020, a população foi estimada em 115.969 habitantes, o que representa um aumento populacional de 17\% nos últimos 10 anos.

\section{Resultados e Discussão}

\subsection{MapBiomas Alerta}

Para analisar e demonstrar como funciona a ferramenta de alerta de desmatamento desenvolvida através do Projeto MapBiomas Alerta, faz-se necessário abordar a metodologia aplicada para emitir os alertas e os laudos. O MapBiomas Alerta analisa os alertas de desmatamento nos Biomas brasileiros por meio de três sistemas de monitoramento: i) ADETER/INPE para a Amazônia e o Cerrado; ii) SAD/IMAZON para a Amazônia; e iii) GLAD/Universidade de Maryland para os Biomas Pampa, Pantanal, Caatinga e Mata Atlântica (MapBiomas, 2019). Esses sistemas garantem a cobertura de alerta em todos os Biomas, com resolução espacial similar e frequência mensal, que podem ser visualizados por recorte territorial ou administrativo (MAPBIOMAS, 2019).

As etapas metodológicas incluem: 1) coleta e agregação dos alertas de desmatamento detectados em cada mês, criação de código identificador único (ID) para cada alerta; 2) pré-validação; 3) validação; 4) refinamento e auditoria; 5) cruzamento com recortes territoriais e administrativos; 6) publicação de todos os alertas e respectivos laudos em uma plataforma web de livre acesso (Figura 4). 
Figura 4: Etapas metodológicas.

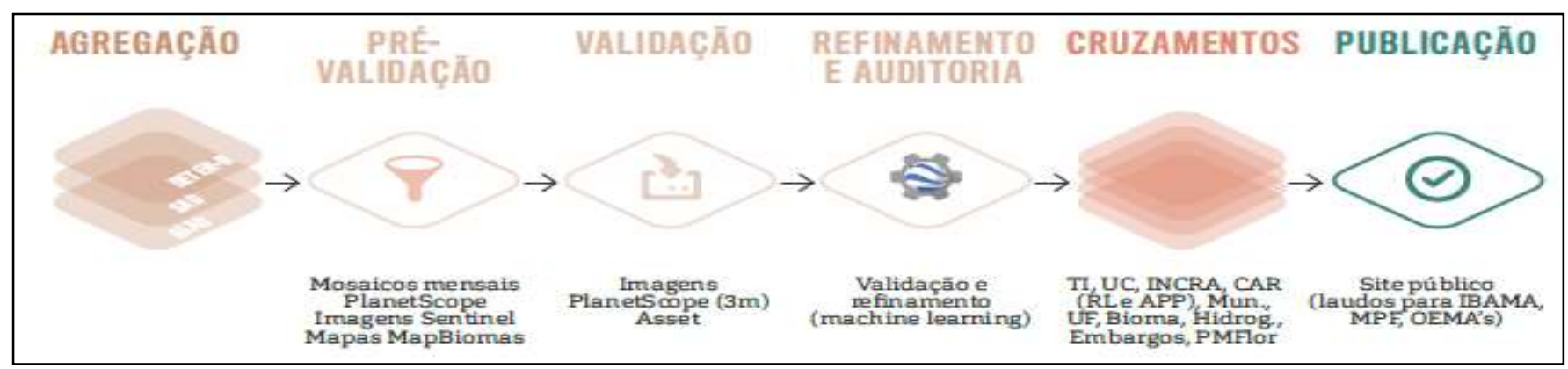

Fonte: Relatório Anual do Desmatamento no Brasil (MapBiomas, 2019).

A plataforma do MapBiomas Alerta disponibiliza laudos com as seguintes informações: localização da área de alerta; imagem da área antes e depois; localização do alerta na propriedade e no estado; cruzamento dos dados da área com informações espaciais fundiárias e de fiscalização; visualização do alerta sobre o mapa base do MapBiomas com a alteração do uso e ocupação do solo nos últimos anos; e memorial descritivo das coordenadas de cada ponto que delimita a área (MAPBIOMAS, 2021b). Dessa forma, abordaremos nos resultados e discussões a partir da utilização dessa ferramenta no contexto do panorama geral do desmatamento nos biomas brasileiros e no recorte territorial do Bioma da Amazônia, do estado do Pará e do município de Altamira - PA, que apresentam as maiores áreas desmatadas no Brasil nos últimos anos.

\subsection{Panorama geral do desmatamento nos Biomas brasileiros}

O panorama geral do desmatamento nos biomas brasileiros apresenta dados preocupantes em relação ao número de alertas emitidos e ao total de áreas desmatadas, que seguem em ritmo crescente. O Brasil soma 131.269 alertas e mais de 2 milhões de hectares de áreas desmatadas (Mapbiomas, 2021a). Isto representa uma área maior que o estado de Sergipe e um pouco menor que o estado de Alagoas, que foi totalmente desmatada, no período entre novembro de 2018 e janeiro de 2021 . A situação mais grave é a do bioma da Amazônia, seguido pelo Cerrado, Mata Atlântica, Caatinga, Pantanal e Pampa (Tabela 1).

Tabela 1: Dados dos alertas emitidos pelo MapBiomas.

\begin{tabular}{c|c|c|c}
\multicolumn{1}{c|}{ Bioma } & $\begin{array}{c}\text { Alertas } \\
\text { (unidades) }\end{array}$ & $\begin{array}{c}\text { Área } \\
\text { Desmatada } \\
\text { (ha) }\end{array}$ & $\begin{array}{c}\text { Velocidade } \\
\text { Média } \\
\text { (ha/dia) }\end{array}$ \\
\hline Amazônia & 106.411 & 1.708 .879 & 2.163 \\
\hline Caatinga & 4.436 & 73.191 & 93 \\
\hline Cerrado & 14.934 & 843.932 & 1.067 \\
\hline Mata Atlântica & 4.873 & 38.179 & 48 \\
\hline Pampa & 157 & 1.761 & 2 \\
\hline Pantanal & 458 & 44.157 & 56 \\
\hline Brasil & 131.269 & 2.710 .099 & 3.429
\end{tabular}

Fonte: Plataforma MapBiomas Alerta, período de 11/2018 a 01/2021, atualizados em 15/02/21.

Os Biomas mais afetados pelo desmatamento, no período em estudo, foram: Amazônia e Cerrado. Esses biomas, que apresentam mais alertas e áreas desmatadas, são, também, os mais atingidos pelos garimpos ilegais e pelo avanço das fronteiras do agronegócio nos últimos anos, segundo Pereira, Coca e Origuéla (2021). Enquanto o Brasil apresenta aumentos alarmantes no percentual de áreas desmatadas, as multas por infrações contra a flora reduziram cerca de 40\% (Werneck, Sordi, Araújo \& Angelo, 2021). Esse é um dos reflexos decorrentes do recente desmonte e militarização do Ibama realizado pelo governo federal.

A política adotada pelo Presidente Bolsonaro (2018-2022) e seu Ministro do Meio Ambiente, Ricardo Salles, para combater o desmatamento e o garimpo ilegal está no contrafluxo, exonerando servidores do Ibama, que seguem a legislação 
ambiental vigente. À exemplo, operações de combate ao garimpo ilegal em terras indígenas, que resultou na destruição de dezenas de equipamentos usados por garimpeiros no Pará e que foi duramente criticada pelo governo, levou a exoneração de Renê Luiz de Oliveira do cargo de coordenador-geral de Fiscalização, e Hugo Loss do cargo de coordenador de Operações (Layrargues, 2020; Werneck et al., 2021).

Ao observar as imagens da consulta ao MapBiomas Alerta, realizada no dia 15 de fevereiro de 2021, nota-se a gravidade da situação do desmatamento no Brasil e como esses alertas estão dispostos no território de cada bioma (Figura 5).

Figura 5: Mapas de alertas de desmatamento por biomas.

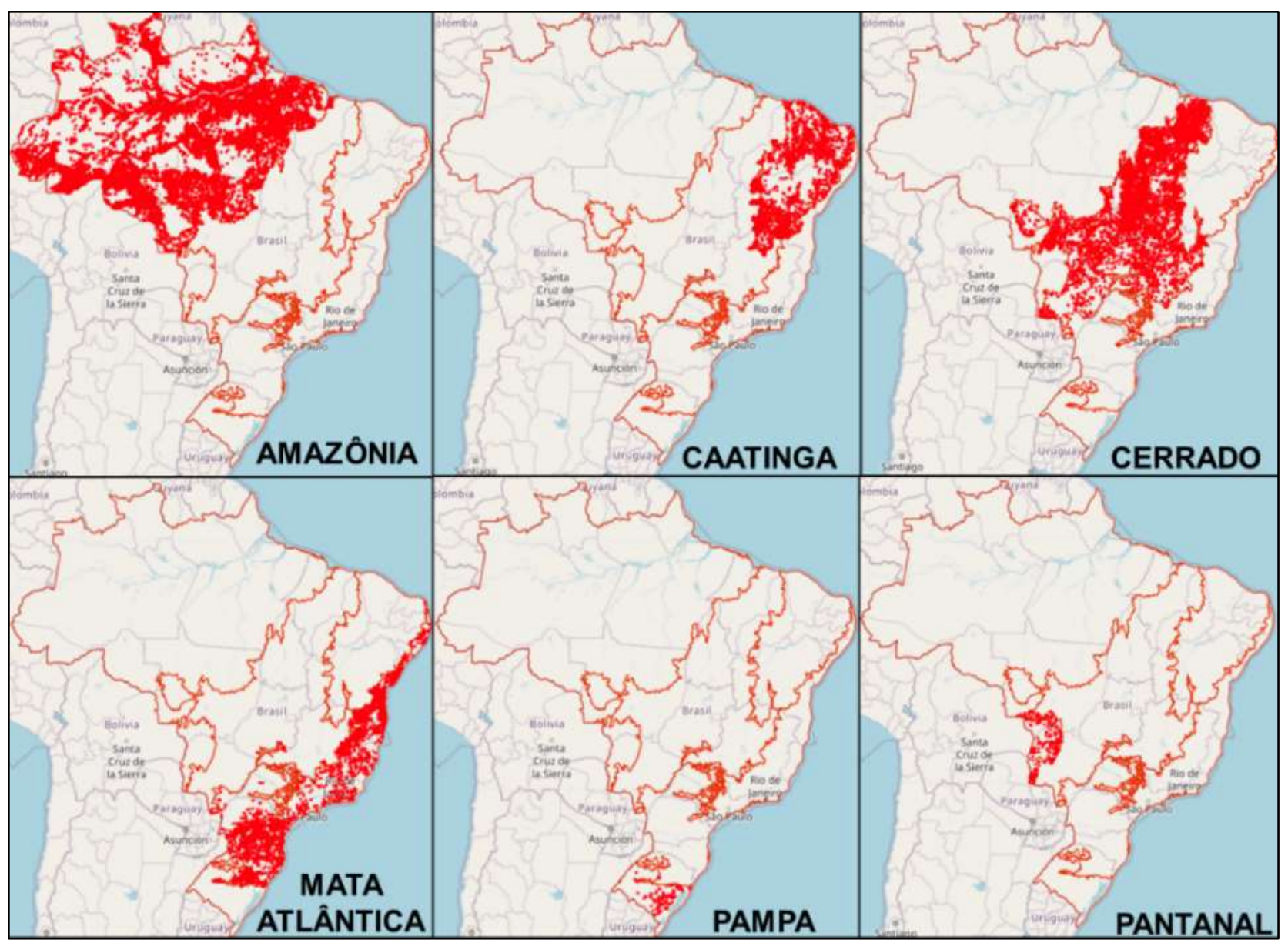

Fonte: imagens organizadas pelos autores, obtidas através da Plataforma MapBiomas Alerta (atualização em 15/02/21).

$\mathrm{Na}$ Amazônia, foram emitidos $81 \%$ dos alertas e $63 \%$ da área desmatada em relação ao percentual total do Brasil está nesse Bioma. A Caatinga apresentou 3,4\% dos alertas e 2,7\% da área desmatada. O Cerrado apresentou 11,4\% dos alertas e 31\% da área desmatada. A Mata Atlântica teve 3,7\% dos alertas e 1,4\% da área desmatada. Pampa e Pantanal apresentaram 0,11\% e 0,34\% dos alertas, respectivamente, e $0,06 \%$ e $1,62 \%$ de área desmatada em relação ao total de área desmatada no Brasil, no período em estudo.

O Governo Federal, na pessoa do presidente Jair Bolsonaro, tem atuado por ações e omissões como um cúmplice do ecocídio em curso, por meio do crescente desmatamento em território brasileiro, e do genocídio, que atinge a população através do Coronavírus. Já que em ambos os casos, ecocídio e genocídio, as autoridades competentes preferiram seguir o caminho do negacionismo científico e se omitir diante das suas responsabilidades.

Embora o Brasil atravesse tempos sombrios no que diz respeito ao contexto político e ambiental, as legislações ambientais foram pioneiras e antecederam o processo de redemocratização brasileira, uma vez que a Política Nacional de Meio 
Ambiente (PNMA) foi instituída em 1981 (Lei N 6.938) e criou o Conselho Nacional de Meio Ambiente (CONAMA), antes da existência da Constituição Federal, criada em 1988 (Imaflora \& ISA, 2021). O CONAMA é um órgão democrático, consultivo e deliberativo, que trouxe importantes contribuições por meio de discussões e definições no âmbito normativo e de padrões compatíveis com o meio ambiente ecologicamente equilibrado e essencial à sadia qualidade de vida.

O CONAMA, assim como outros conselhos deliberativos, também foi alvo de reformulações do governo Bolsonaro, que reduziu de 93 para 23 o número de conselheiros (Decreto $N^{\circ}$ 9.806/2019). Enquanto a sociedade civil e os Estados perderam representação, o governo e o setor produtivo passaram a ser maioria (Werneck et al., 2021). É dessa forma que o governo tem aparelhado os Conselhos e Comitês deliberativos, que fazem parte do Ministério de Meio Ambiente, reduzindo a participação social e a democratização desses espaços. Pois prefere atuar por meios antidemocráticos, com decretos e portarias presidenciais.

\subsection{Panorama do Bioma, do estado e do município com maiores áreas desmatadas}

Dentre os biomas brasileiros que apresentaram alertas de desmatamento, o Bioma da Amazônia é o que apresenta o maior número de alertas e a maior área desmatada (Figura 6). O Pará está entre os estados que concentram grandes reduções de vegetação e foi de onde partiu o alerta da maior área desmatada (MapBiomas, 2021a).

Figura 6: Bioma, estado e município que apresentam maior área desmatada.

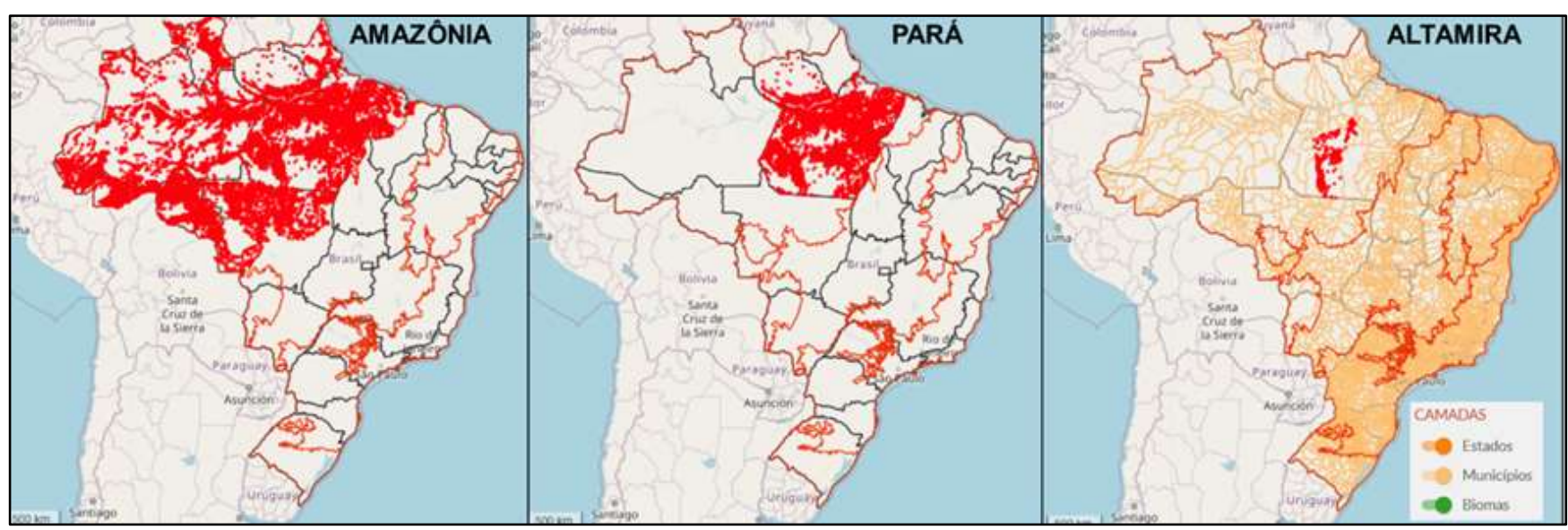

Fonte: imagens organizadas pelos autores, obtidas através da Plataforma MapBiomas Alerta (atualização em 15/02/21).

Os dados apresentados pelo laudo do MapBiomas Alerta são de extrema importância para o monitoramento do desmatamento nos Biomas brasileiros, pois, trata-se de uma ferramenta que permite que os dados georreferenciados de áreas desmatadas sejam acessados com facilidade por profissionais da área ambiental e por pessoas civis. Essa ferramenta apresenta grande potencial e pode ser utilizada de forma educacional para ensinar estudantes e técnicos da área ambiental a acessar essa plataforma e alertá-los para a gravidade do desmatamento no Brasil, que tem devastado grandes áreas em todos os biomas e gerado inúmeros problemas socioambientais.

O município de Altamira, que é o maior município brasileiro, com área total de 159.533,328 Km² , apresentou em um dos seus alertas uma área desmatada de $44,5 \mathrm{Km}^{2}$, que corresponde a 6.232 estádios de futebol. Uma área florestal dessa dimensão foi totalmente suprimida, perdeu toda cobertura vegetal nativa e se transformou em uma grande área degradada no meio da Floresta Amazônica, em Altamira - PA (Figura 7). Esse é o exemplo de um dos maiores alertas emitido pelo MapBiomas. Porém, além desse, há outros milhares de alertas, que conseguem mapear as áreas desmatadas em Altamira, no Pará e em todo o Brasil. 
Figura 7: Antes e depois da área desmatada em Altamira-PA.

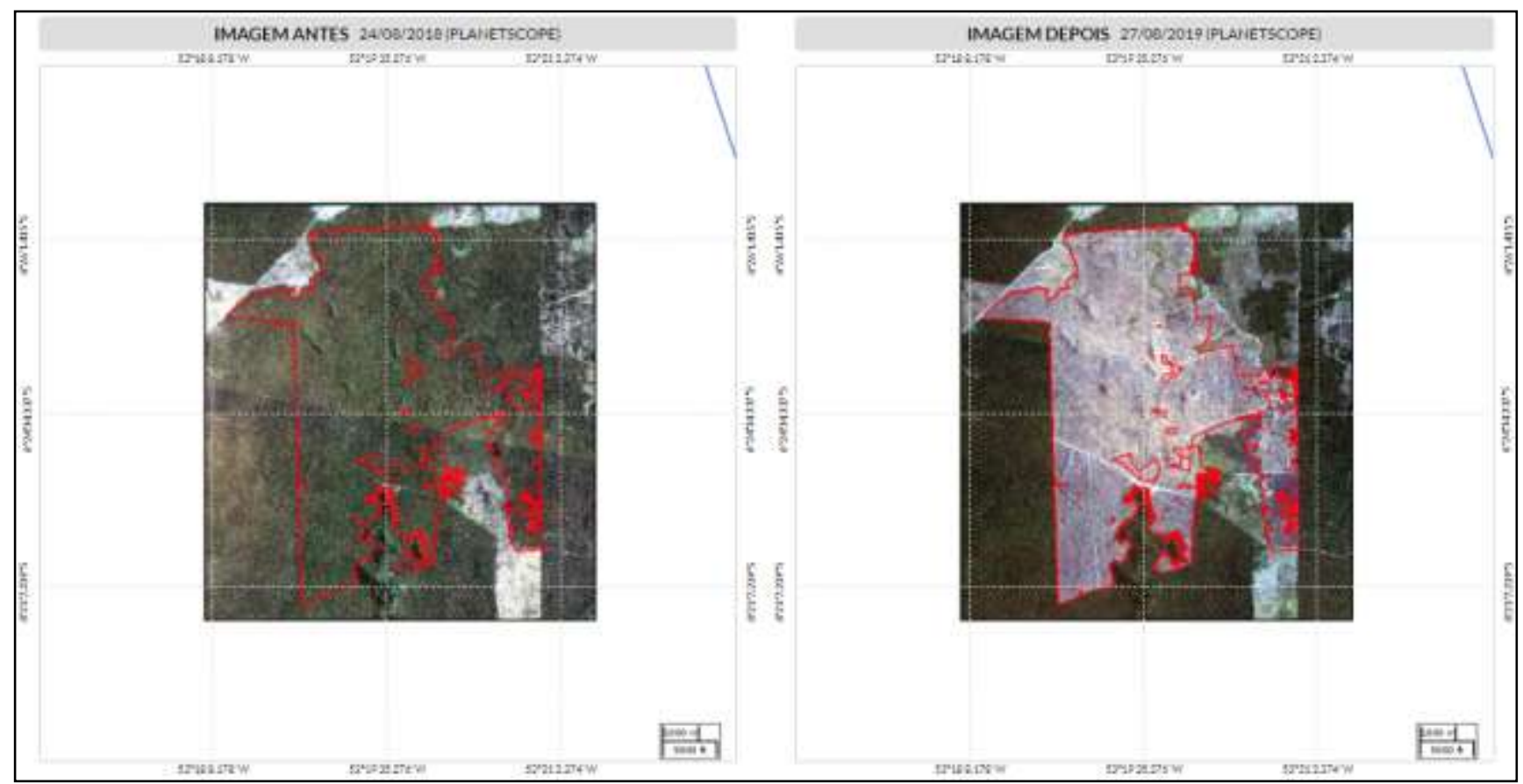

Fonte: Plataforma MapBiomas Alerta, laudo acessado em 24/01/2021, ID do alerta: 27847.

Os alertas do município de Altamira - PA, consultados em 01 de abril de 2021, somam um total de 2.833 alertas, que correspondem a uma área total de 118.754 hectares desmatados $\left(1187,54 \mathrm{Km}^{2}\right)$. Essa área corresponde, aproximadamente, a área de 166.322 estádios de futebol, e é cerca de 27 vezes maior que a área desmatada, que aparece na Figura 6, que faz parte do laudo em estudo, gerado automaticamente pelo MapBiomas Alerta.

O laudo do MapBiomas Alerta também apresenta a localização do alerta na propriedade e no Estado, e mostra todos os dados que compõem a área desmatada, que fazem parte das bases de dados georreferenciados acessadas pela plataforma MapBiomas, que tem como fonte: o IBGE; FUNAI; CNUC/MMA; INCRA; SFB; Sinaflor/IBAMA; e SEMA (Figura 8). Os dados de localização são de extrema importância para que os órgãos de fiscalização embarguem a área e multem os responsáveis pelo desmatamento. Permitem, também, que a área seja monitorada ao longo dos anos e que seja gerado o histórico de uso e ocupação da área.

Além disso, o laudo emite o cruzamento dos dados de alertas, que permitem a caracterização da área, se é composta, por exemplo, por terras indígenas, nascentes de rios, Reserva Legal, Unidades de Conservação e Área de Preservação Permanente. Se teve autorização para realizar a supressão de vegetação, se possui áreas embargadas e se tem Plano de Manejo Florestal. No caso em estudo, a área é composta por 8.902,55 hectares de área de Unidade de Conservação, 4.299,74 hectares de área de Reserva Legal, sendo que 51 áreas já haviam sido embargadas no imóvel, ou seja, é uma área que possui um histórico de incidência de desmatamento (Figuras 8 e 9). 
Figura 8: Localização do alerta na propriedade e no estado.

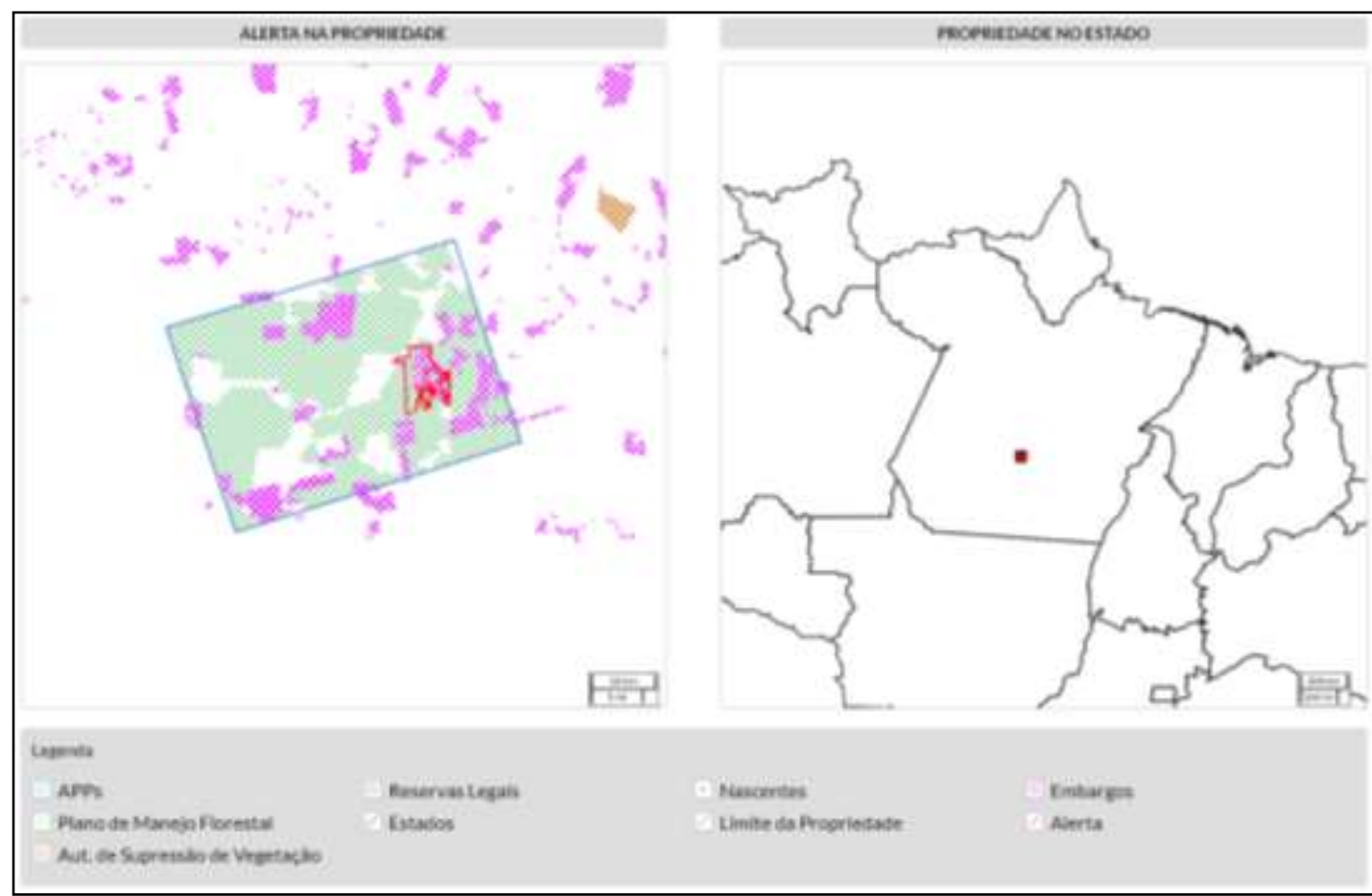

Fonte: Site MapBiomas Alerta, laudo acessado em 24/01/2021, ID do alerta: 27847.

O cruzamento de alertas inclui: limites de Terras Indígenas (TI), de Unidades de Conservação (UC), de assentamentos rurais, das áreas do Cadastro Ambiental Rural (CAR), contemplando inclusive as Áreas de Preservação Permanente (APP) e de Reserva Legal (RL) declaradas, além de áreas de embargos, autorizações de supressão e planos de manejo florestal, contidos na base de dados do Sinaflor do Ibama (Figura 9).

Figura 9: Cruzamento do alerta com os dados da área.

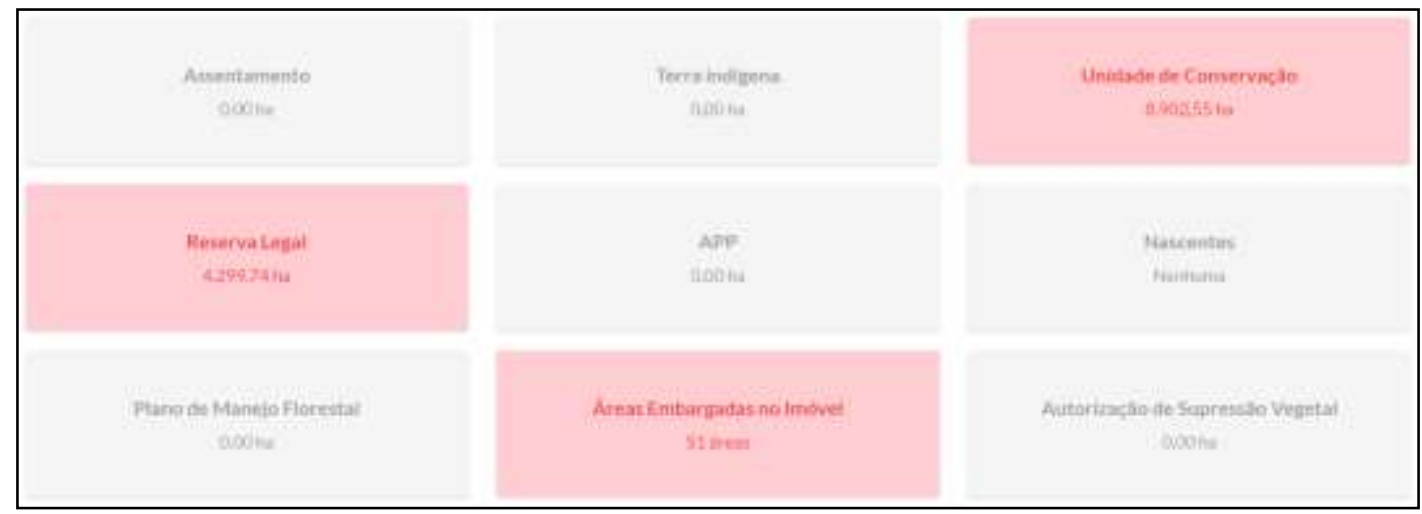

Fonte: Site MapBiomas Alerta, laudo acessado em 24/01/2021, ID do alerta: 27847.

O laudo apresenta um histórico de imagens da área (2012 - 2018), com as classes: Vegetação Nativa; Floresta Plantada; Agropecuária; e Áreas Não Vegetadas. Essas imagens são importantes para monitorar as mudanças de uso e ocupação do solo na área em estudo e nos Biomas, de modo geral. No entanto, o laudo em estudo não apresenta variação de imagens, como os dados são gerados automaticamente, pode ter ocorrido um erro no processamento das imagens históricas do laudo (Figura 6). Dessa forma, essas imagens, especificamente, não permitem analisar as mudanças no uso e ocupação do solo na área desmatada ao longo dos anos. Mas, a Figura 10, permite conhecer, simultaneamente, um dos potenciais e uma das fragilidades da Plataforma 
MapBiomas Alerta: permitir a visualização do alerta na área e das classes de uso e ocupação do solo ao longo dos anos, precisa que as bases de dados sejam atualizadas, pelo menos uma vez ao ano, com as informações das classes de uso e ocupação do solo nas áreas.

Figura 10: Visualização do alerta sobre o mapa base MapBiomas (2012 - 2018).

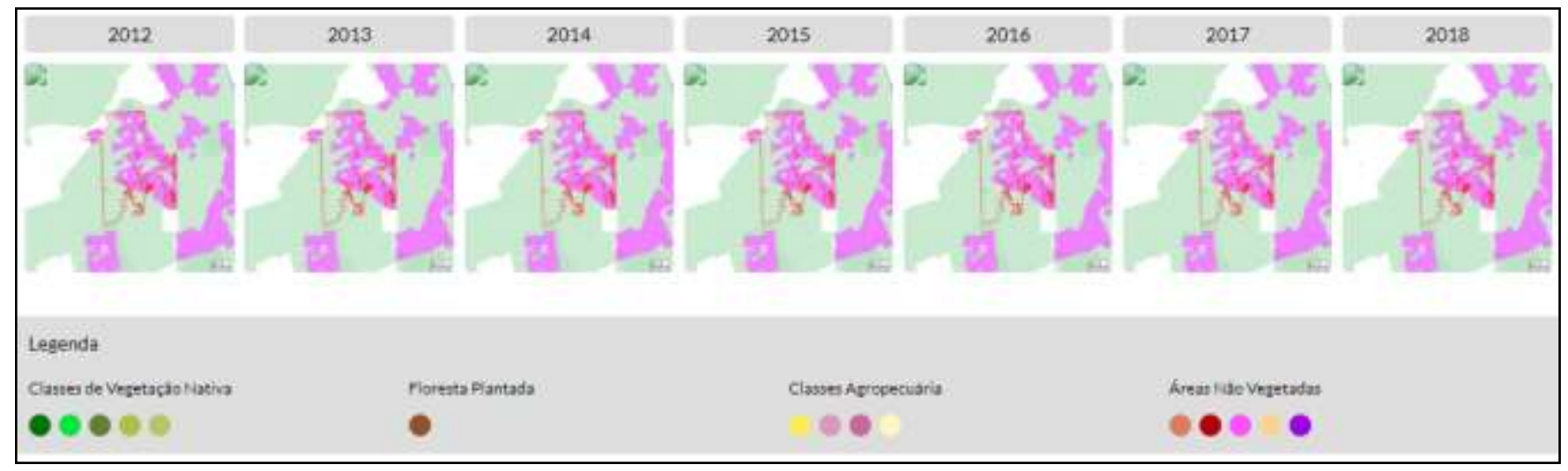

Fonte: Site MapBiomas Alerta, laudo acessado em 24/01/2021, ID do alerta: 27847.

Outro dado relevante gerado automaticamente pelo laudo do MapBiomas Alerta é o memorial descritivo com a marcação e as coordenadas dos pontos, que limitam o polígono da área desmatada (Figura 11).

Figura 11: Memorial Descritivo com a marcação da área e coordenadas dos pontos.

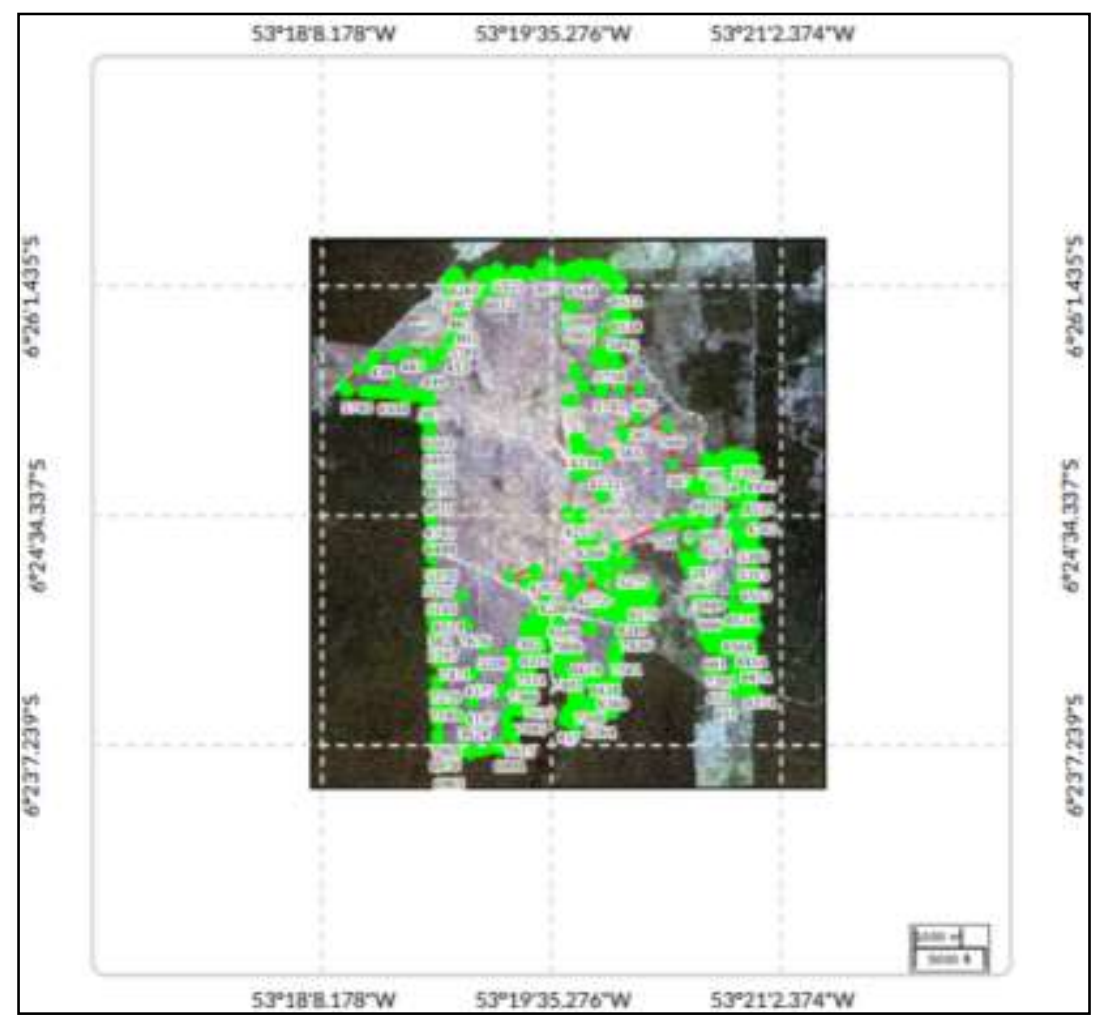

Fonte: Plataforma MapBiomas Alerta, laudo acessado em 24/01/2021, ID do alerta: 27847.

Com os dados do laudo é possível localizar exatamente onde está a área desmatada, identificar características da propriedade e o histórico de desmatamento da área. O que facilita o trabalho dos órgãos responsáveis pela fiscalização, já que o 
laudo apresenta dados de fontes confiáveis (Figura 12) e de extrema importância para o monitoramento do desmatamento nos Biomas brasileiros.

Figura 12: Fonte de dados.

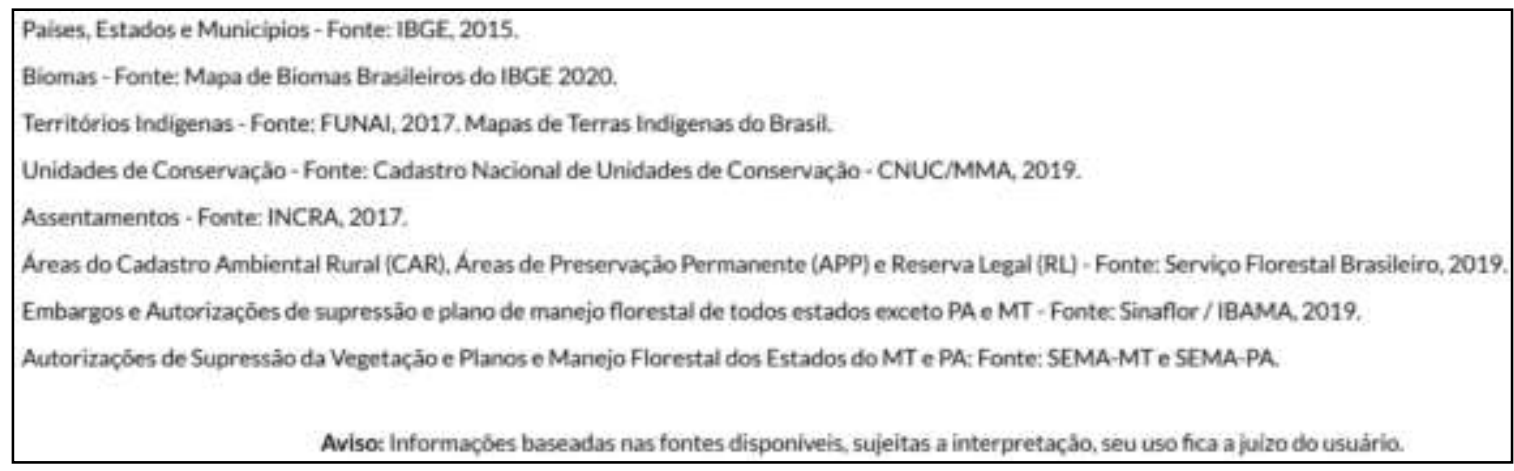

Fonte: Plataforma MapBiomas Alerta, laudo acessado em 24/01/2021, ID do alerta: 27847.

Tal situação de destruição das florestas naturais em território brasileiro é um reflexo do contexto político do Brasil nos últimos anos e que tem contribuído para o aumento do desmatamento. Já que tem ocorrido desmonte das políticas públicas e dos órgãos ambientais, que tem sido alvo de censura e da militarização institucional, principalmente os órgãos responsáveis pelo monitoramento e fiscalização do desmatamento. Como ocorreu, por exemplo, com o Instituto Nacional de Pesquisas Espaciais (INPE), que teve a exoneração do Diretor Ricardo Galvão, em 2019, após divulgação de dados que revelavam o aumento do desmatamento na Amazônia, e sofreu cortes orçamentários (Werneck et al., 2021).

O Instituto Brasileiro do Meio Ambiente e dos Recursos Naturais Renováveis (Ibama), que é um dos órgãos que atuam no combate ao desmatamento, controle ambiental e licenciamento, foi submetido ao Ministério de Defesa e teve cargos de chefia ocupados por militares. O Instituto Chico Mendes de Conservação da Biodiversidade (ICMBio), que é responsável pelas Unidades de Conservação do país e espécies ameaçadas, teve cortes orçamentários e cargos de chefia ocupados por militares (Aragão, Silva Junior \& Anderson, 2020).

O desmonte, a militarização e a redução da transparência de órgãos ambientais, por meio de censuras institucionalizadas em códigos de ética impostos aos servidores, dificultam a publicidade de dados que deveriam ser abertos, por serem de interesse público. A Lei $N^{\circ}$ 12.527, de 2011, regulamentou o Acesso à Informação, como um direito fundamental que deve ser assegurado por todos os órgãos públicos através da transparência. Além disso, a Política Nacional de Dados Abertos, instituída em 2016, pelo Decreto Federal n ${ }^{\circ} 8.777$, obriga os órgãos federais a elaborar Plano de Dados Abertos (PDAs) (Imaflora \& ISA, 2021). No entanto, com o início do governo de Jair Bolsonaro, o Brasil tem recuado em relação aos avanços que apresentava na transparência e democratização dos dados de órgãos ambientais de extrema importância para monitorar, fiscalizar, combater e punir ações de desmatamento.

\section{Considerações Finais}

A iniciativa do MapBiomas Alerta traz grandes contribuições para o monitoramento do desmatamento nos Biomas brasileiros, possibilitando que cada alerta de desmatamento possa ser verificado, refinado e validado com imagens de alta resolução espacial. Além disso, os laudos gerados podem ser utilizados pelos órgãos competentes para fiscalizar, multar e embargar áreas desmatadas. Um dos problemas é que nem todos os biomas apresentam monitoramento contínuo, apenas Amazônia, Cerrado e Mata Atlântica. Além disso, os polígonos que demarcam os biomas apresentam a mesma cor dos pontos que marcam as áreas de alerta, ambos são vermelhos, o que dificulta a compreensão da imagem. 
O MapBiomas Alerta demonstra na prática como as geotecnologias de Sensoriamento Remoto e os Sistemas de Informações Geográficas (SIGs) estão cada vez mais interligadas e suas aplicações nos diferentes campos do conhecimento seguem em ritmo crescente. A utilização do SIG facilita a integração de dados de sensores remotos como àqueles provenientes de outras fontes. Os dados, uma vez inseridos no sistema, são manipulados com mais agilidade e de forma mais eficiente, além do sistema possibilitar o uso de ferramentas matemáticas e de estatísticas, auxilia no processo de tomada de decisão e permite a atualização dos dados e produção de mapas com rapidez (Hamada \& Gonçalves, 2007). Essas ferramentas estão cada vez mais acessíveis para a população brasileira por meio de aplicativos de smartphone e/ou softwares e plataformas, que podem ser acessados pelo computador, conectado à rede de internet. Assim como aplicativos de GPS tornaram-se populares e são bastante utilizados por grande parte dos brasileiros, a facilidade para o acesso e o uso do MapBiomas Alerta são características importantes para que essa ferramenta fique cada vez mais popular, tanto no meio acadêmico como no meio social, de forma geral.

$\mathrm{O}$ avanço das geotecnologias e o número crescente de satélites e sensores geoespaciais, aliados a ampliação da capacidade de processamento e armazenamento de dados, contribuíram para a disseminação do uso dessas tecnologias (Tosto, Rodrigues, Bolfe \& Batistella, 2014). Isso só foi possível, pois alguns dos dados de sensores remotos e SIGs, que até pouco tempo eram de uso exclusivo de instituições públicas e privadas, com acesso restrito aos técnicos e pesquisadores dessas instituições, hoje são de livre acesso e de uso comum. Ou seja, é cada vez mais importante a democratização do acesso à informação e aos dados ambientais, principalmente, quando se trata de algo que é do interesse de todos, como é o caso do controle e monitoramento do desmatamento nos biomas brasileiros.

No entanto, enquanto o desmatamento teve o seu ritmo acelerado, o atual governo paralisou os órgãos ambientais de fiscalização e combate ao desmatamento. O Plano de Prevenção e Controle do Desmatamento na Amazônia (PPCDAm), maior responsável pela queda de 83\% do desmatamento de 2004 a 2012, segundo Werneck et al. (2021), encontra-se extinto, mesmo sem ter sido revogado formalmente. O Fundo Amazônia foi paralisado pela Alemanha e a Noruega, que não concordaram com declarações do Presidente Bolsonaro e do Ministro Ricardo Salles, por possuir cláusulas que impedem mudanças de regra sem comum acordo, o Fundo não pode ser alterado pelo governo e está desde o início de 2019 sem aprovar projetos.

São grandes os esforços do governo federal para inviabilizar o acesso aos dados ambientais e ferramentas que permitam o monitoramento de áreas degradadas. Como alterações nos protocolos de comunicação de órgãos ambientais, elevação do sigilo de dados e documentos, apagões em bases de dados e deslegitimação dos órgãos ambientais (Imaflora \& ISA, 2021). Desde o dia primeiro de janeiro de 2019, quando Jair Bolsonaro assumiu a presidência do Brasil, os limites da desregulação ambiental começaram a ser testados por seu governo (Bronz, Zhouri \& Castro 2020).

Coincidentemente, no dia 22 de abril de 2019 (data que marca a chegada dos portugueses ao território brasileiro, há mais de 500 anos), ocorreu uma reunião Ministerial, marcada por diálogos que dizem muito sobre as posturas adotadas pelo governo Bolsonaro. O Ministro do Meio Ambiente, Ricardo Salles, disse que era para aproveitar a pandemia e "passar as reformas infralegais de desregulamentação, simplificação...”. Solicitou esforços dos demais ministros e do presidente, enquanto o momento era de tranquilidade no aspecto de cobertura de imprensa, já que só se fala da pandemia, e ir passando a boiada, mudando todo o regramento e simplificando normas. Já o Ministro da Educação da época, Abraham Weintraub, falou: “Odeio o termo 'povos indígenas', odeio esse termo. Odeio. O ‘povo cigano'. Só tem um povo nesse país. Quer, quer. Não quer, sai de ré. É povo brasileiro, só tem um povo". Um governo escolhido a dedo pelo presidente Jair Bolsonaro, que se elegeu com a promessa que não haveria 1 centímetro de terra demarcada para os povos indígenas, entre outras promessas e atos com graves impactos socioambientais, que vem cumprindo. Um governo movido pelo ódio aos povos indígenas e ao meio ambiente, seria essa a definição de governo genocida e ecocida? 


\section{Agradecimentos}

O presente trabalho foi realizado com o apoio do Programa de Pós-graduação em Engenharia e Gestão de Recursos Naturais (PPGEGRN), da Universidade Federal de Campina Grande (UFCG). Nossos agradecimentos aos órgãos de fomento à pesquisa, que contribuem para o desenvolvimento científico no Brasil, em especial a Coordenação de Aperfeiçoamento de Pessoal de Nível Superior - Brasil (CAPES) - Código de Financiamento 001.

\section{Referências}

Aragão, L. E. O. C., Silva Junior, C. H. L., Anderson, L. O. (2020). O desafio do Brasil para conter o desmatamento e as queimadas na Amazônia durante a pandemia por COVID-19 em 2020: implicações ambientais, sociais e sua governança. São José dos Campos, 2020. 34p. SEI/INPE: 01340.004481/202096/5543324. 10.13140/RG.2.2.11908.76167/1

Bloomfield, L. S. P., McIntosh, T. L. \& Lambin, E. F. (2020). Habitat fragmentation, livelihood behaviors, and contact between people and nonhuman primates in Africa. Landscape Ecol 35, 985-1000. https://doi.org/10.1007/s10980-020-00995-w

Bronz, D., Zhouri, A., \& Castro, E. (2020). Apresentação: Passando a boiada: violação de direitos, desregulação e desmanche ambiental no Brasil. Antropolitica - Revista Contemporânea de Antropologia, 49, https://doi.org/10.22409/antropolitica2020.i49.a44533

Florenzano, T. G. (2007). Iniciação em Sensoriamento Remoto. Oficina de Textos.

Florenzano, T.G (2005). Geotecnologias na geografia aplicada: difusão e acesso. Revista do Departamento de Geografia, 17, 24-29. https://doi.org/10.7154/RDG.2005.0017.0002

Hamada, E., Gonçalves, R. R. V. (2007). Introdução ao geoprocessamento: princípios básicos e aplicação. Jaguariúna: Embrapa Meio Ambiente, 52 (Embrapa Meio Ambiente. Documentos, 67).

IBGE. Biomas Brasileiros. (2021). https://educa.ibge.gov.br/jovens/conheca-o-brasil/territorio/18307-biomas-brasileiros.html

Imaflora \& ISA (2021). Mapeamento dos retrocessos e transparência e participação social na política ambiental brasileira - 2019 e 2020. pp. 35. imaflora.org/public/media/biblioteca/mapeamento_dos_retrocessos_de_transparencia_e_participacao_social_na_politica_ambiental_.pdf

Layrargues, P. P. (2020). Pandemias, colapso climático, antiecologismo: educação ambiental entre as emergências de um ecocídio apocalíptico. Revista Brasileira de Educação Ambiental (Revbea), 15(4), 01-30. https://doi.org/10.34024/revbea.2020.v15.10861

MAPBIOMAS. (2019). Relatório Anual do Desmatamento no Brasil, 2019. 49 p. https://s3.amazonaws.com/alerta.mapbiomas.org/relatrios/MBI-relatoriodesmatamento-2019-FINAL5.pdf

MAPBIOMAS. (2021a). Sobre o Projeto MapBiomas Alerta. http://alerta.MapBiomas.org

MAPBIOMAS. (2021b). Laudo MapBiomas Alerta. https://plataforma.alerta.mapbiomas.org/laudos/120740

Miranda Neto, J. Q., \& Herrera, J. A. (2017). Expansão urbana recente em Altamira (PA) Novas tendências de crescimento a partir da instalação da UHE Belo Monte. Ateliê Geográfico, 11(3), 34-52. https://doi.org/10.5216/ag.v11i3.33766

Miranda Neto, J. Q., \& Herrera, J. A. (2016). Altamira-PA: novos papéis de centralidade e reestruturação urbana a partir da instalação da UHE Belo Monte, Confins [Online], 28. https://doi.org/10.4000/confins.11284

Pereira, L. I., Coca, E. L. de F., \& Origuéla, C. F. (2021). O “passar a boiada” na questão agrária brasileira em tempos de pandemia. Revista NERA, 24(56), 0823, https://doi.org/10.47946/rnera.v0i56.8314

Resende, M (2002). 500 Anos de Uso do Solo no Brasil. In: Araújo, Q. R. (Ed.), 500 anos de uso do solo no Brasil. Ilhéus: Editus, pp. 1-50.

Redding, D. W., Atkinson, P. M., Cunningham, A. A., et al. (2019). Impacts of environmental and socio-economic factors on emergence and epidemic potential of Ebola in Africa. Nat Commun 10, 4531. https://doi.org/10.1038/s41467-019-12499-6

Romão, E. P., Pontes, A. N., Gutjahr, A. L. N., \& Torres, W. R. G. (2017). Análise temporal do uso e da cobertura do solo nas áreas desflorestadas do município de Altamira, Pará. Enciclopédia Biosfera, Centro Científico Conhecer. 14(25), 113 - 126. 10.18677/EnciBio_2017A11

Souza, C. M., Shimbo, J. Z., Rosa, M. R., Parente, L. L., Alencar, A. A., Rudorff, B. F., Hasenack, H., Matsumoto, M., Ferreira, L. G., \& Souza-Filho, P. W. (2020). Reconstructing Three Decades of Land Use and Land Cover Changes in Brazilian Biomes with LandsatArchive and Earth Engine. Remote Sens. 12 (17), 2735, https://doi.org/10.3390/rs12172735

Tosto, S. G., Rodrigues, C. A. G., Bolfe, E. L., \& Batistella, M. (2014). Geotecnologias e Geoinformação: o produtor pergunta, a Embrapa responde / editores técnicos, 248 il. - (Coleção 500 Perguntas, 500 Respostas).

Werneck, F., Sordi, J., Araújo, S., \& Angelo, C. (2021). "Passando A Boiada": O segundo ano de desmonte ambiental sob Jair Bolsonaro. Observatório Do Clima, pp. 38. 